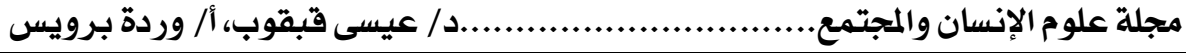

\title{
فعالية الاتصال الإداري في المؤسسة الصناعية
}

الدكتور : عيسى قبقوب، جامعة بسكرة، الجزائر

الأستاذة: وردة برويس، جامعة بسكرة، الجزائر

الملخص:

يهدف هذا المقال إلى دراسة فعالية الاتصال الإداري في المؤسسة الصناعية

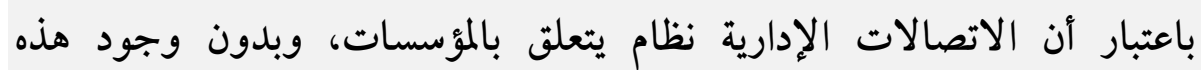

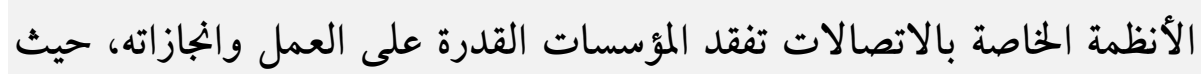

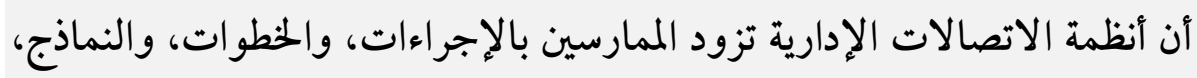

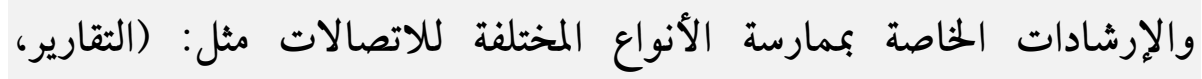
والرسائل، والمذكرات، والاجتماعات).

\section{Abstract:}

This article aims to study the effectiveness of the administrative contact in Industrial Corporation as the system of communication in regard to the institutions, and without the existence of these regulations relating to communications the institutions lose its ability to work and achievements. The administrative communication systems provide practitioners with steps, forms, and instructions for the exercise of the different types Communications such as: (reports, letters, memos, meetings). 


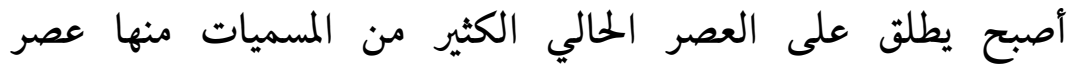

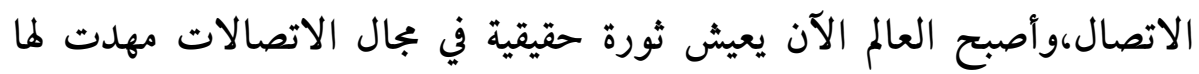

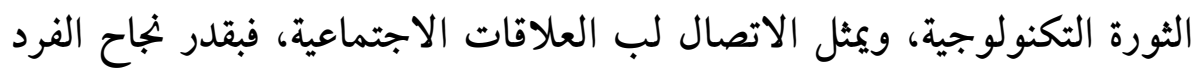

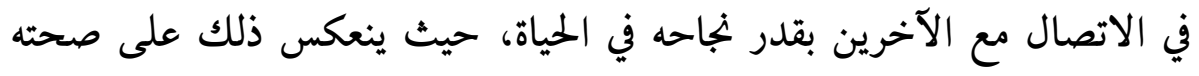

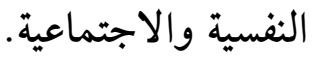

ولا تخلو أي مؤسسة صناعية من تلك العملية التي يتفاعل من خلالالها

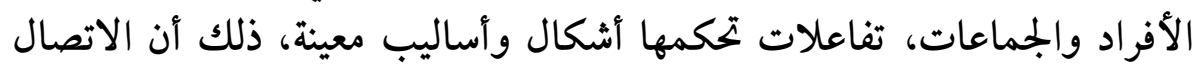

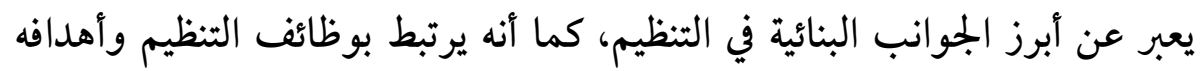

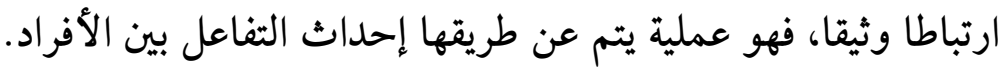

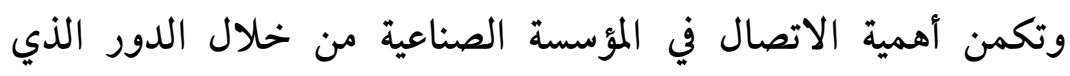

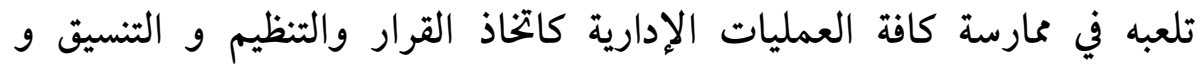

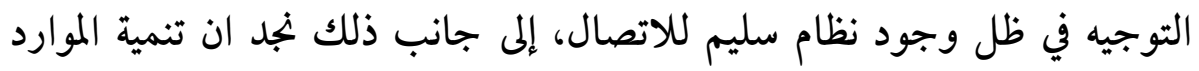

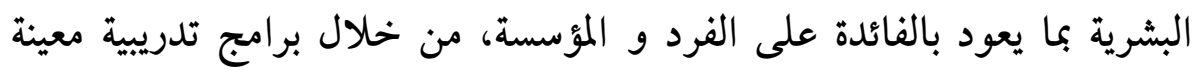

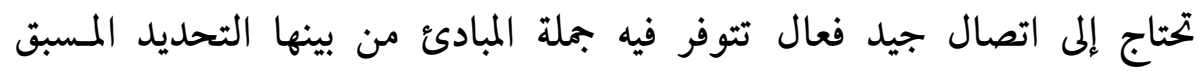
للأهداف وحسن الإرسال للمعلومات وفهمها.

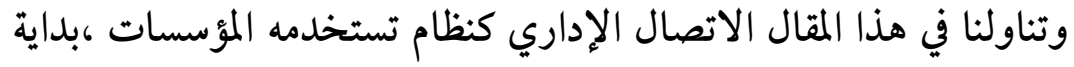

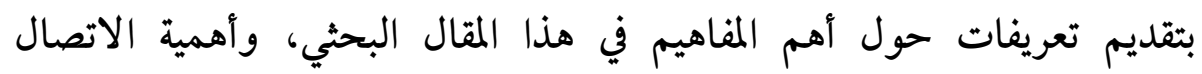

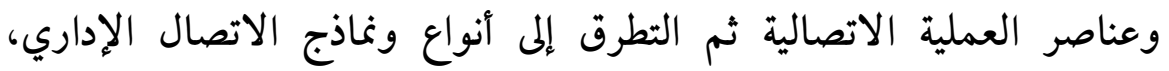

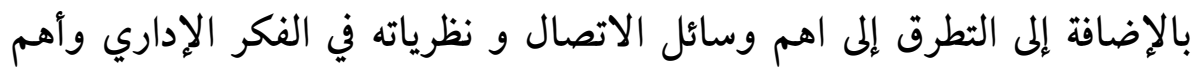

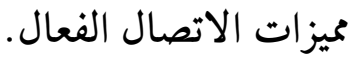

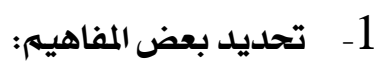

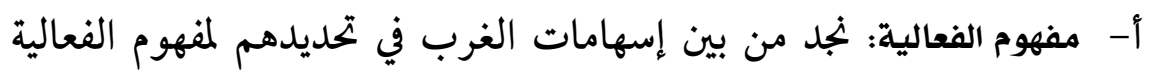
مايلي: - non 
يعرفها ايتزيوني Aatzione: بأنها قدرة المنظمة على تحقيق أهدافها وتعتمد

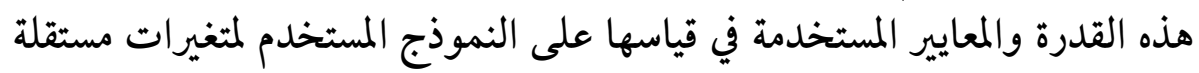

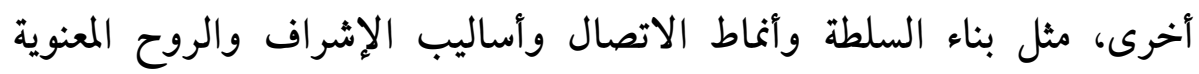

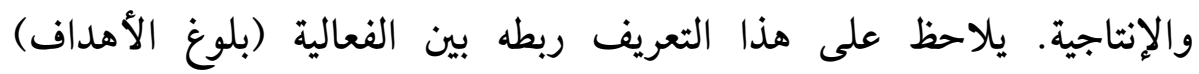

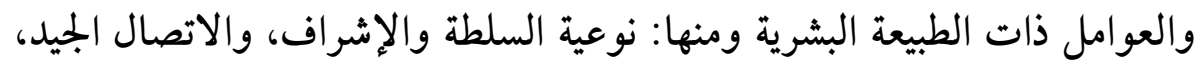

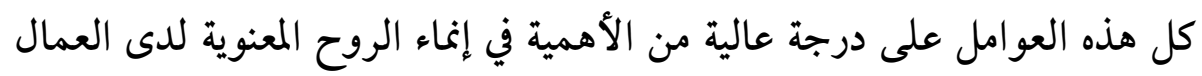
مما يحفزهم على بذل الجهل على لتحقيق أهداف المؤسسة.

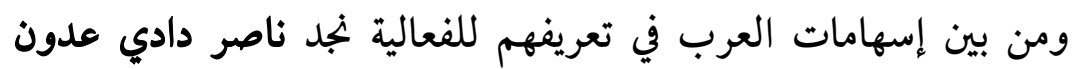

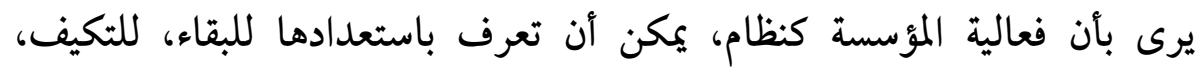

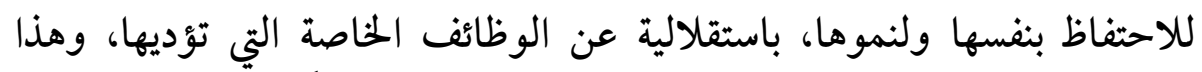

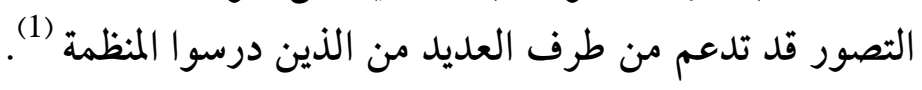
مفهوم الاتصال: توجد إسهامات عديدة من العلماء الغربيين لتعريف الاتصال

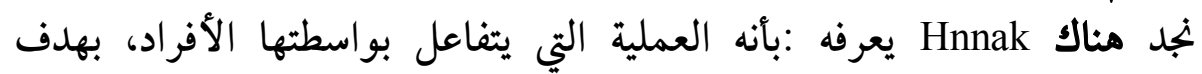

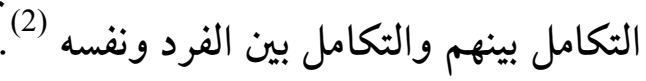

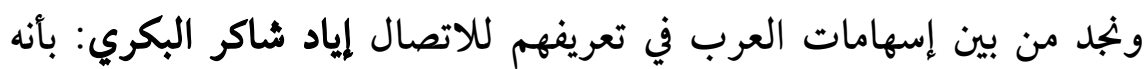

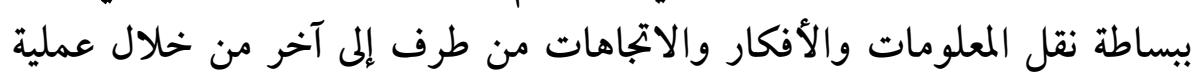
ديناميكية مستمرة ليس لما بداية أو نهاية (3). ويشير هذا التعريف إلى أن الاتصال عملية تفاعل بين طرفين، حيث الماند يصبح المرسل مستقبلا والمستقبل مرسلا وهكذا.

ج- مفهوم الاتصال الإداري: يرى الدكتور محمود سلمان العميان،بأن الاتصال

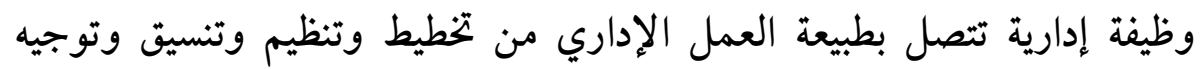

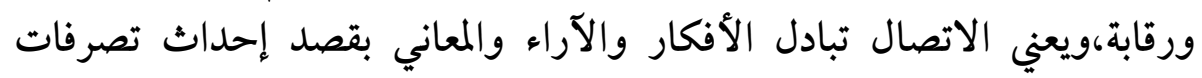

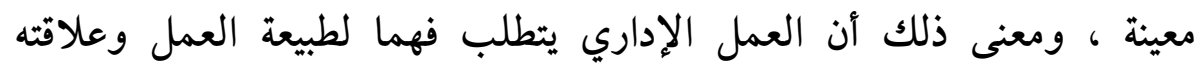

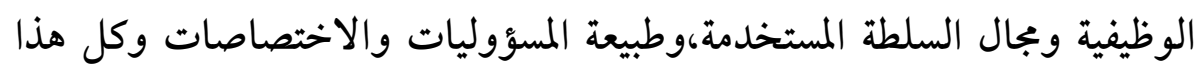




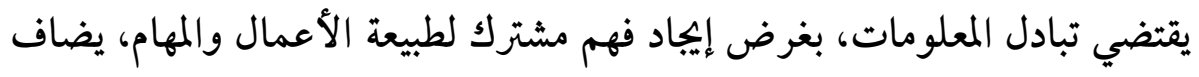

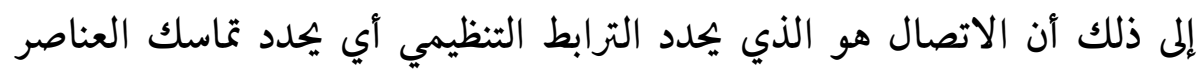

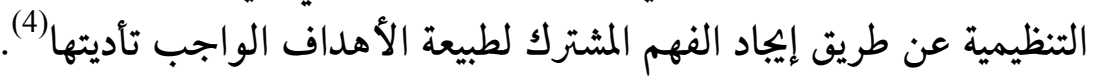
وعليه فإن الاتصال الإداري في المؤسسة الصناعية هو عملية اجتماعية

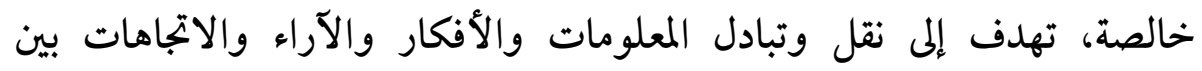

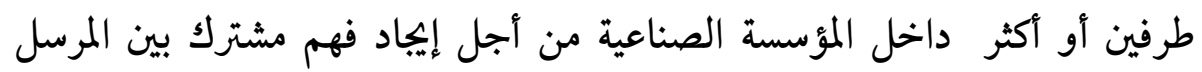

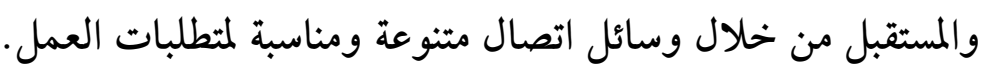

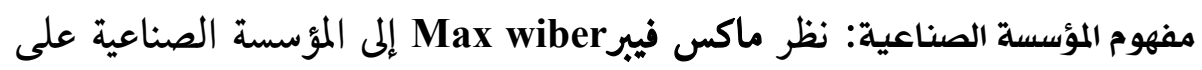

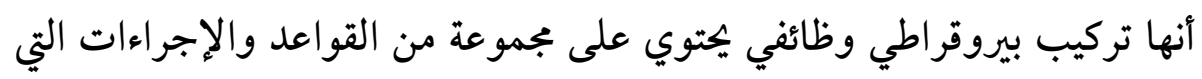

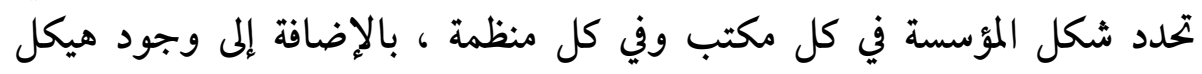

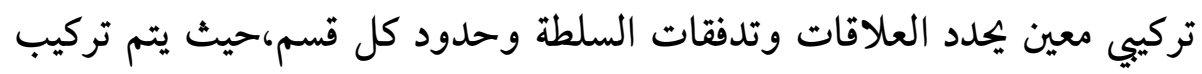

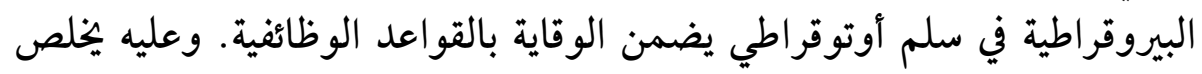

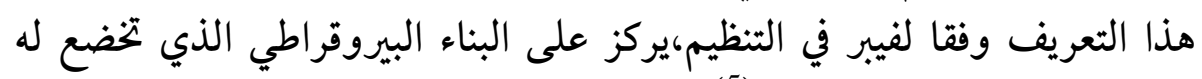
المنظمات لتحديد المسؤوليات (5) فئين 2. أهمية الاتصال و عناصر العملية الاتصالية:

أممية الاتصال:تمثل عملية الاتصال الرباط الذي يربط مختلف الأجهزة

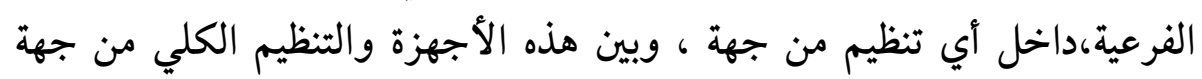

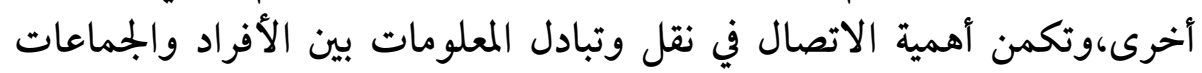

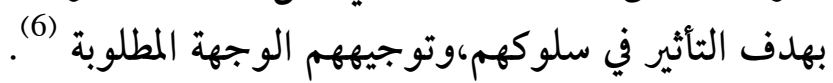

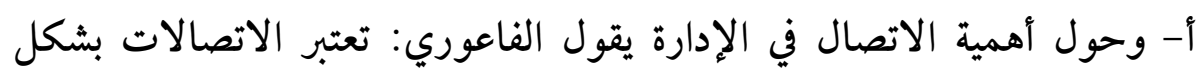

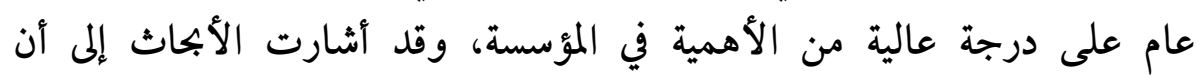

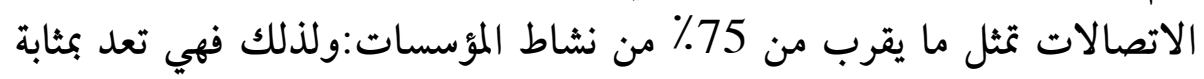

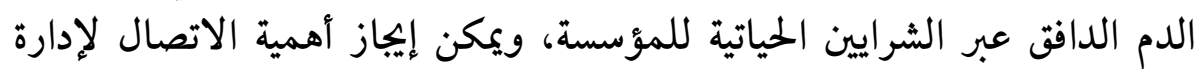

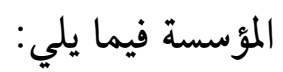




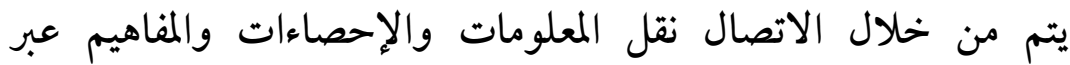
القنوات المختلفة، مما يسهم بشكل في اتخاذ القرارات الإدارية وتحقيق

$$
\text { نجاح المؤسسة ونموها وتطورها. }
$$

تساهم الاتصالات في إحكام المتابعة والسيطرة على الأعمال التي يمارسها

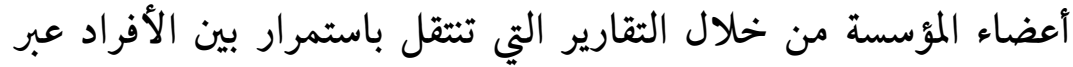

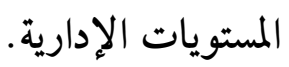

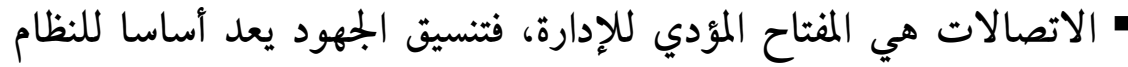

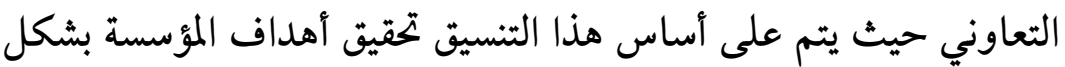

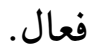

يتم من خلال عملية الاتصال، اطلاع الرئيس على نشاط مرؤوسيه كما

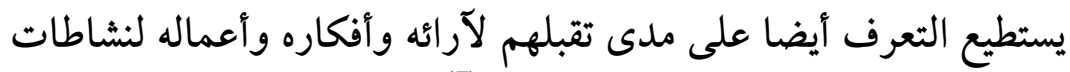

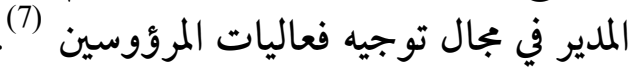

يوفر الاتصال مع التكنولوجيا فرصة للاتصال بين الموظفين سواء كانوا

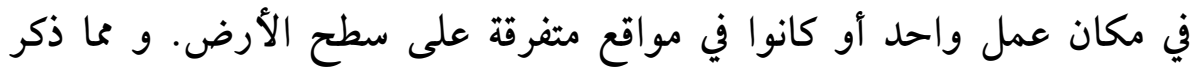

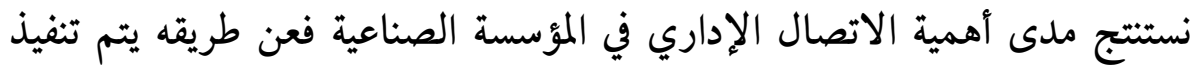

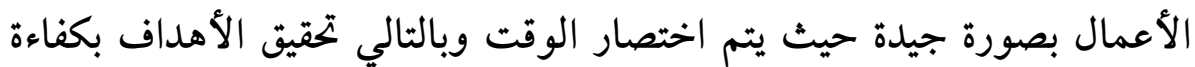
عالية. أ- عناصر العملية الاتصالية:سنتناول مكونات العملية الاتصالية كما يلي:

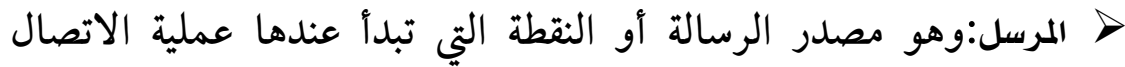
عادة، وقد يكون هذا المصدر هو الإنسان أو الآلة أو المطبوعات أو غيات المير الماتهال ذلك (8) الرسالة: وهي بجموعة من الأفكار والمفاهيم والمهارات أو المبادئ أو القيم

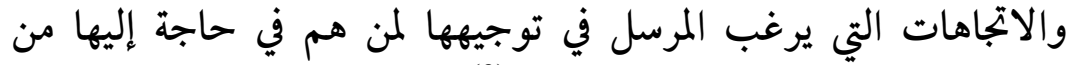

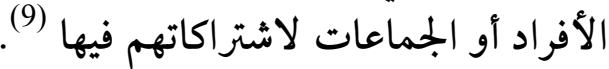


> تحديد وسيلة الاتصال: هي ما تؤدى به الرسالة أو القناة التي تحمل الرموز

التي تحتويها الرسالة من المرسل إلى المستقبل (10).

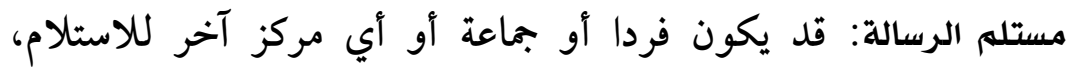

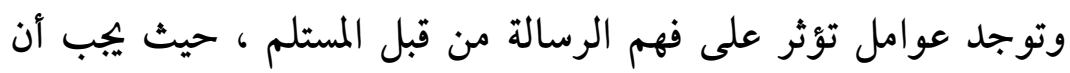

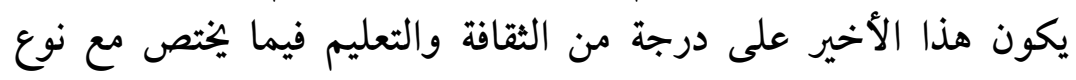

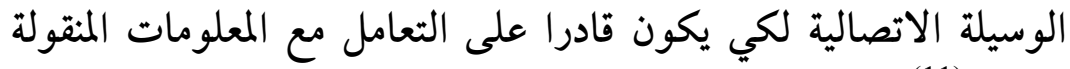

بكفاءة (11) الانصائ

تحليل الرموز وفهمها (فك رموز الرسالة): عندما تصل الرسالة إلى المستقبل

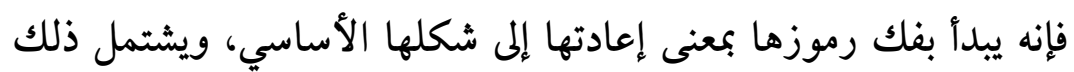

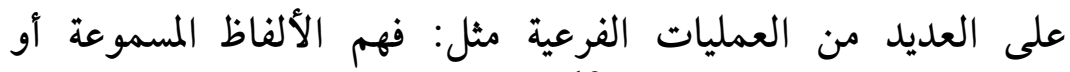
المقروءة،وشرح تعبيرات الوجه (12). التغذية العكسية: تعتبر التغذية العكسية جزءا لا يتجزأ من عملية الاتصال ليعلم المرسل نتائج العمل الذي قام به (13).

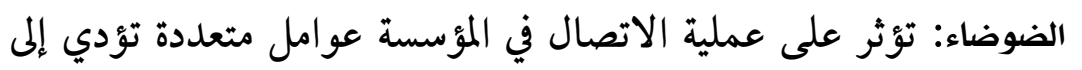

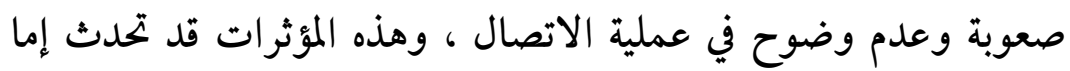
من المرسل أو من خلال عملية الإرسال أو عند استلام الرسالة (14). 3.أنواع الاتصال الإداري ونماذجه:

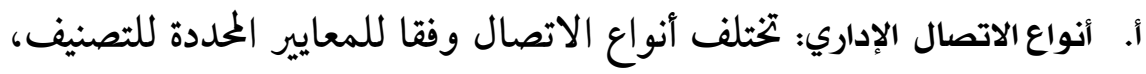
ويككن تصنيف أنواع الاتصال الإداري وفقا للمعايير التالية: > أنواع الاتصال وفقا للغة الستخدمة:بكن تقسيم الاتصال حسب اللغة إلى

اتصال لفظي: وهو الذي يستخدم فيه اللفظ أو الكلمة كوسيلة لنقل الرسالة من المصدر إلى المستقبل، وينقسم إلى نوعين: 
اتصال شفهي: وفي هذا النوع من الاتصال يصل اللفظ منطوق إلى

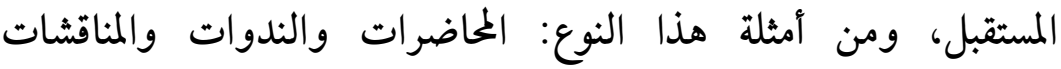

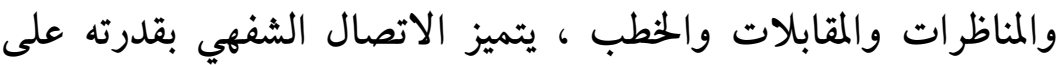

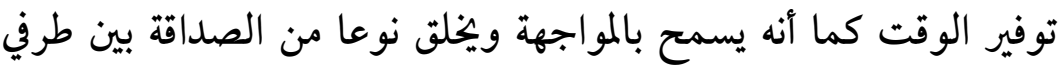

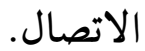

اتصال كتابي: يعمل على نقل المعلومة المطلوبة إلى عدد كبير من الأفراد

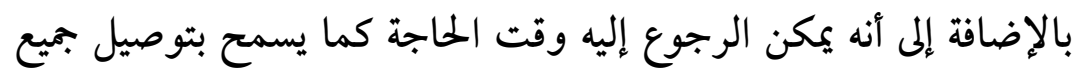

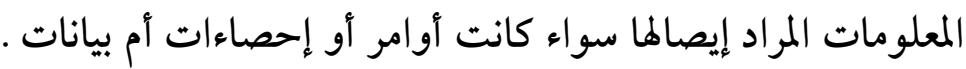

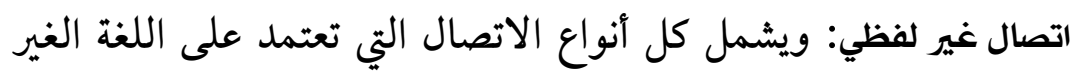

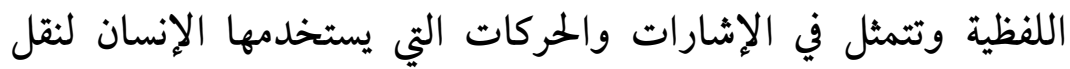

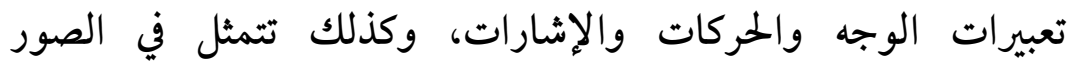

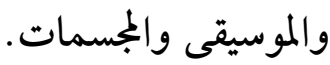

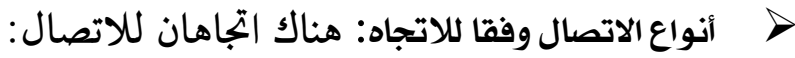

الاتصال من طرف واحد: يكون تدفق المعلومات والتوجيهات فيه بصورة

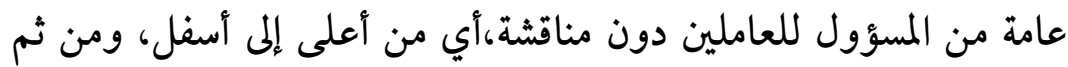

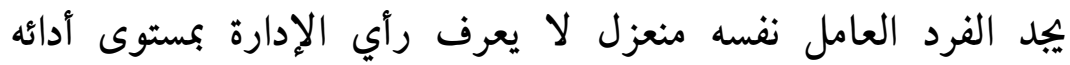

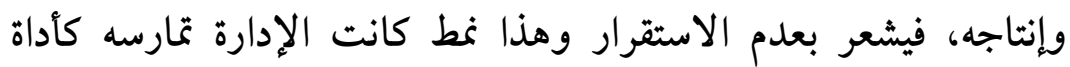

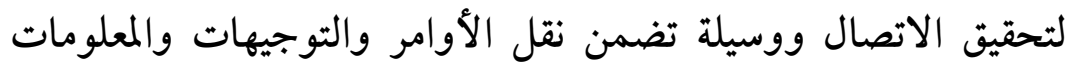
من المسؤولين إلى العاملين (16.

الاتصال في اتجاهين:تتدفق المعلومات فيه من الإدارة للعاملين ومن

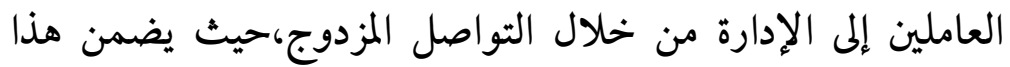

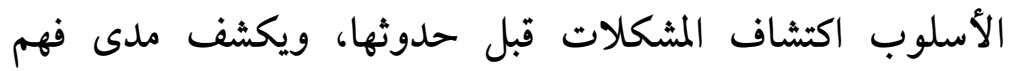

وتجاوب العاملين للرسالة التوجيهية التي اشتركوا في مناقشتها. > أنواع الاتصال وفقا لطبيعة مصدر الرسالة:تنقسم إلى ما يلي: 
الاتصال الرسمي: يتم من خلال خطوط السلطة ونطاق الإشراف وتأخذ

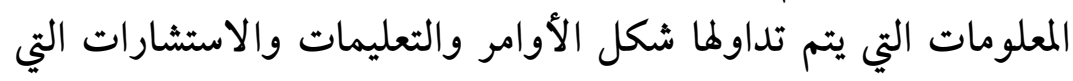

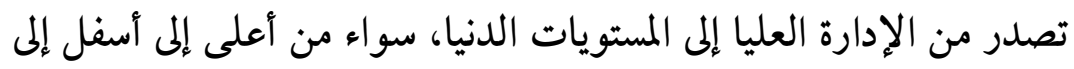
أعلى أو في شكل أفقي (17).

الاتصال غير الرسمي: تعتبر الاتصالات الغير الرسمية أسرع من أنماط

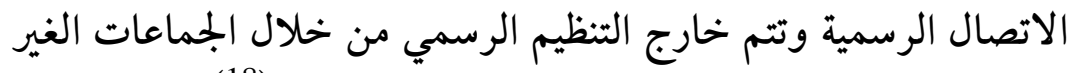

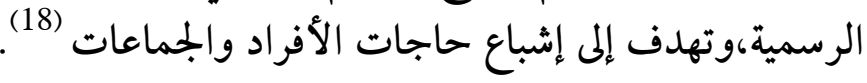
أنواع الاتصال وفقا للنطاق: وتنقسم إلى اتصالات خارجية و اتصالات داخلية: الاتصالات الخارجية: الاتصال هنا لا يقتصر فقط على العلاقات بين

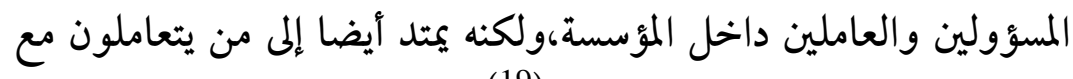
المؤسسة الإدارية من جمهور المنتفعين (19).

الاتصالات الداخلية: يقصد بها الاتصالات داخل المؤسسة لتحقيق أهدافها ومنها إقامة الروح المعنوية العالية للعاملين داخل المؤسسة (20). نماذج الاتصال:من بين الإسهامات العلمية لتصميم نموذج الاتصال مايلي: نموذج لاسويل Laswil: قدم لاسويل منظورا عاما للاتصال تجاوز حدود

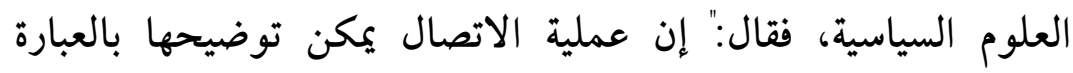

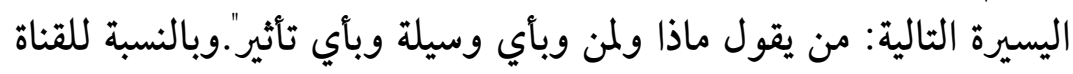

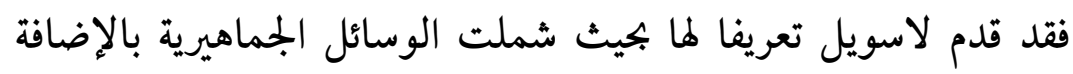

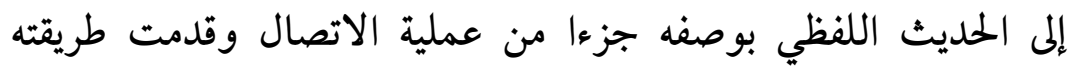

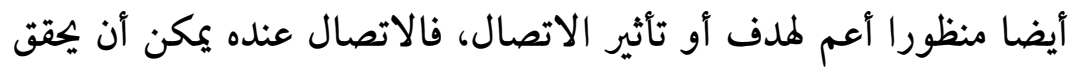
الإعلام أو التسلية والإشارة والإقناع (21). نموذج شانون وويفر claude Elwood Shannon - werren weaver: 
لقد تمكن شانون خلال عمله في فك الشفرات السرية من صياغة

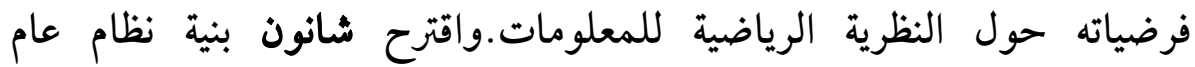

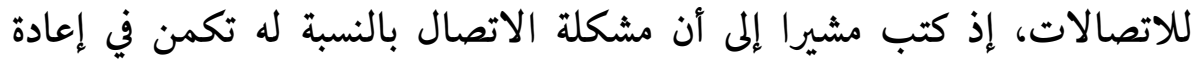

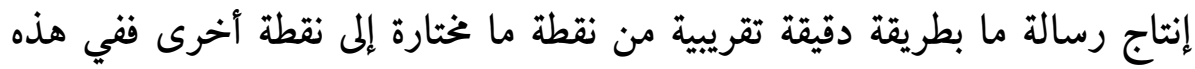

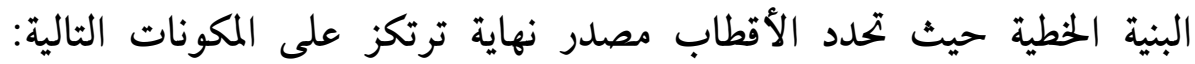

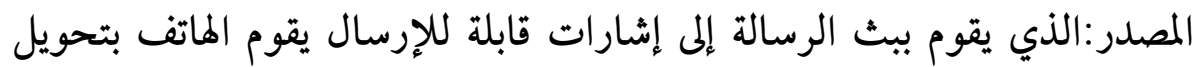

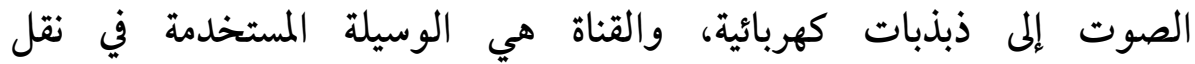

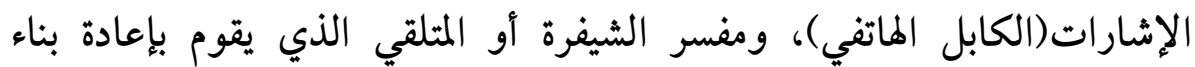

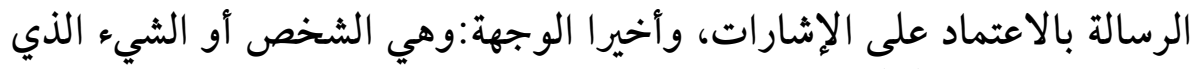
تنتقل إليه الرسالة (22).

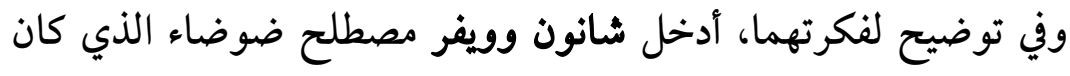

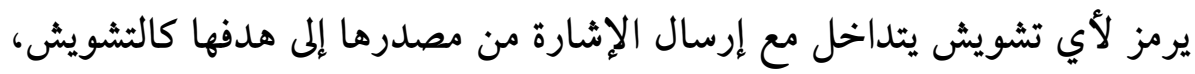

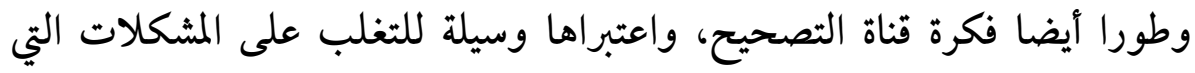

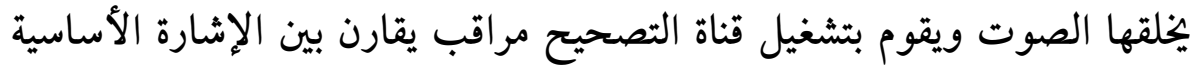

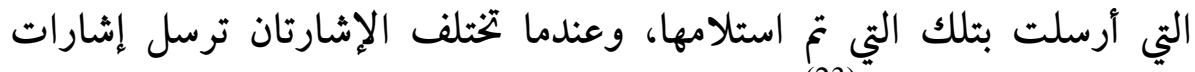
إضافية لتصحيح الخطأ (23).

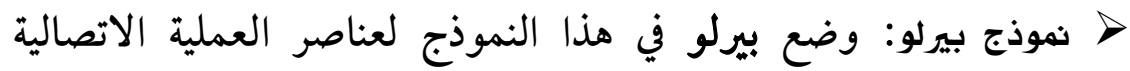

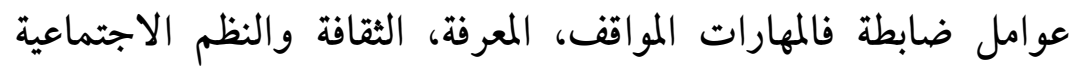

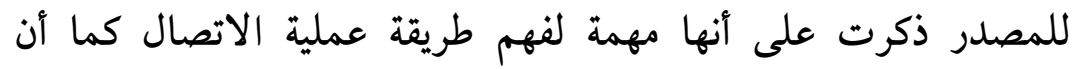

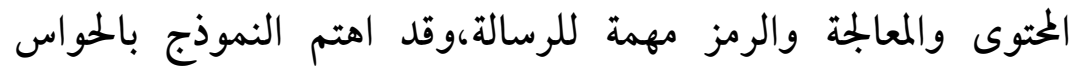

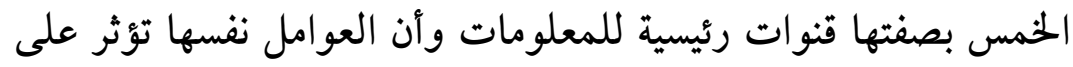

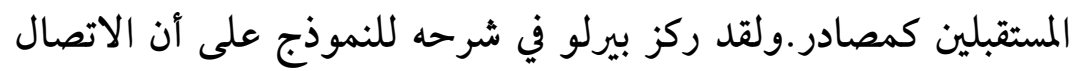

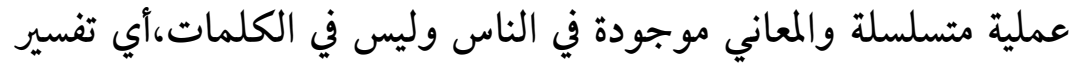

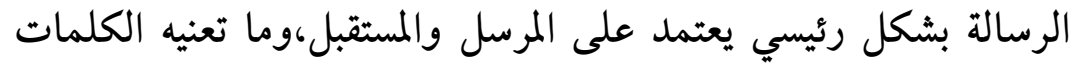
لمما أكثر منهم اعتمادها على عناصر الرسالة (24). 
4. وسائل ونظريات الاتصال ومميزات الاتصال الفعال: أ- وسائل الاتصال:يمكن إجمال هذه الوسائل كما يلي: - الوسائل الاتصالية المكتوبة : تتخذ أثكال متنوعة منها : التقارير: تعتبر من الوسائل الأساسية في العمل الإداري حيث تعمل على الحي

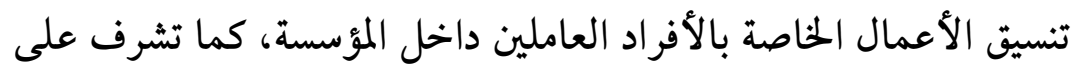

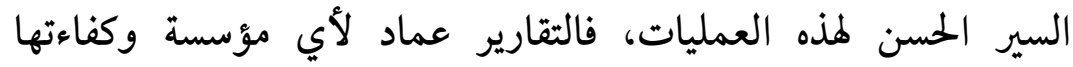

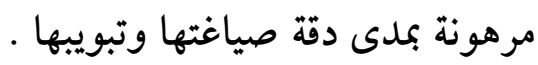

التلكس: من مميزاته أنه مكتوب ومسجل، فهو لهذه الناحية أفضل من

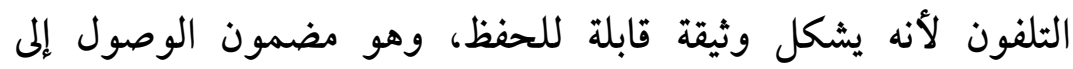

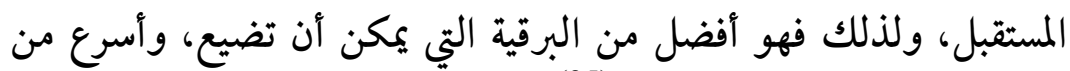

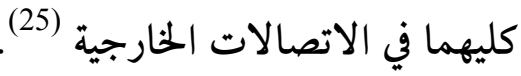

لوحة الإعلانات: تفيد في بث ونشر الإعلانات الرسمية للمؤسسة

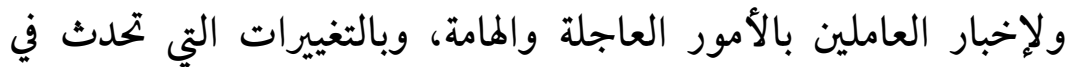

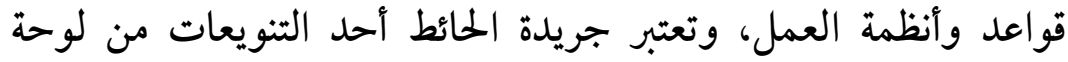

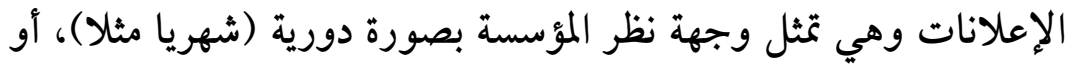
قد تمثل وجهة نظر وتعليق العاملين ونقابتهم أو صناديق الزمالة حول الموضوعات التي تهم علاقة العاملين بالمؤسسة.

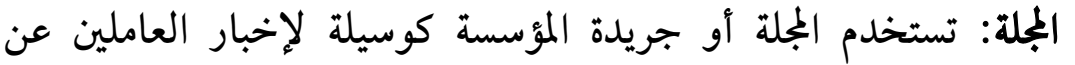

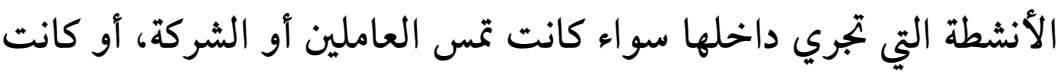

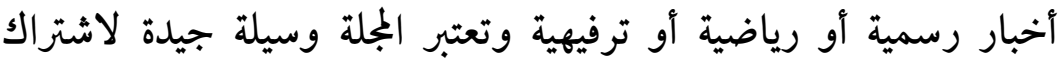

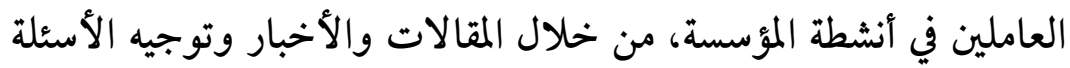
وكتابة التعليقات وغيرها (26). وسائل الاتصال الشفوية : من أمثلة الاتصالات الشفوية مايلي: 
الهاتف: يعتبر من أهم وسائل الاتصال الشفوية، حيث يتميز بالسرعة في

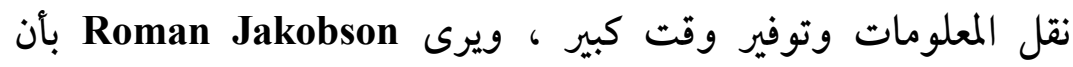

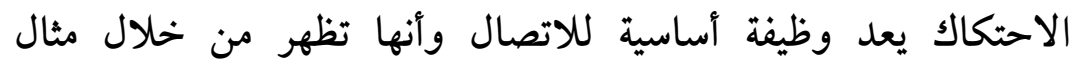

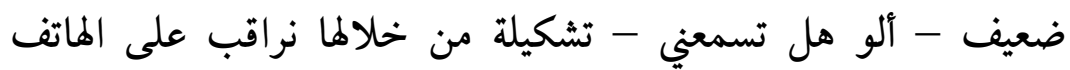
الوظيفة الجيدة للخط (Daniel Bougnoux,1998:22)، في كل مرئي مرة يؤكد

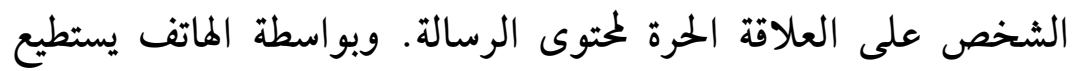

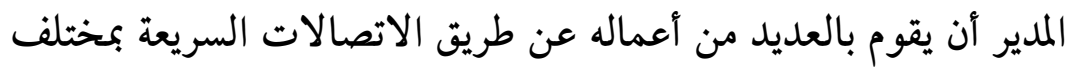

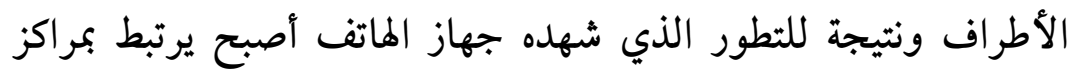

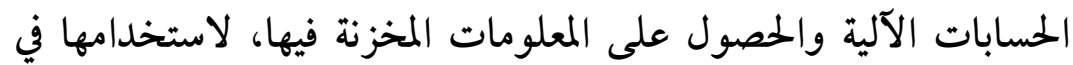
خختلف أغراض التخطيط واتخاذ القرارات (27). الاجتماعات: تعتبر من الوسائل اللفظية وتعتمد على المناقشات، يتم

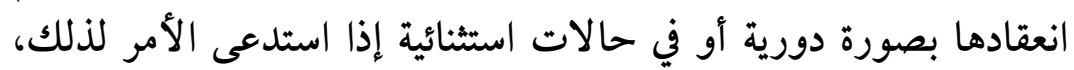

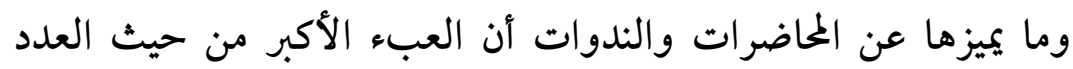
والدراسة والمناقشة يقع على عاتق الأعضاء. المقابلات الجماعية: تكون في شكل هيئة اجتماعات، كما قد تعقد في

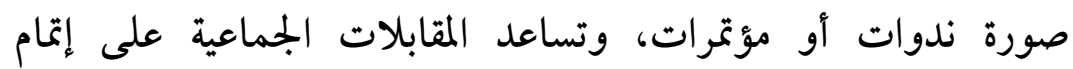

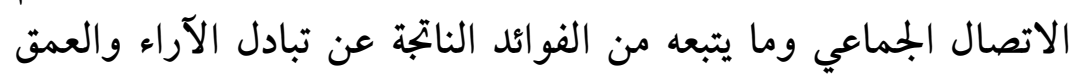

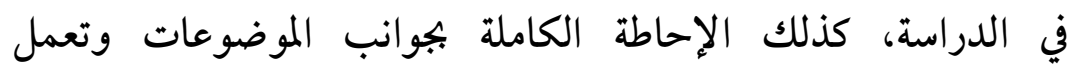

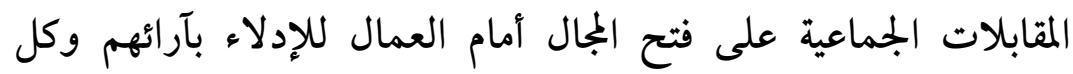

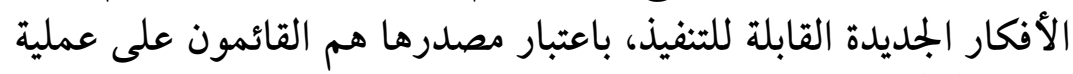
التنفيذ الافنار (28).

المقابلات الشخصية: وهي وسيلة اتصال تحدث وجها لوجه يتم فيها

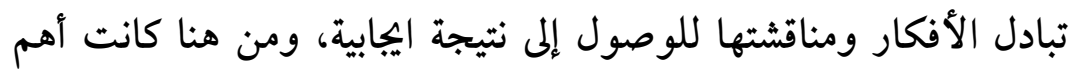

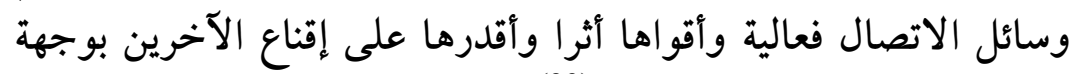
نظرنا ، أو اقتناعنا بوجهة نظرهم (29). 
هالاتصال الصور: تولي المؤسسات لهذا النوع من الاتصال أهمية بالغة،

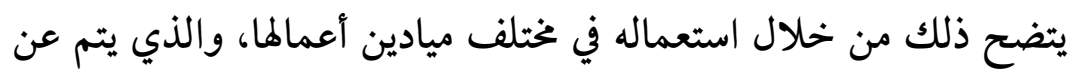

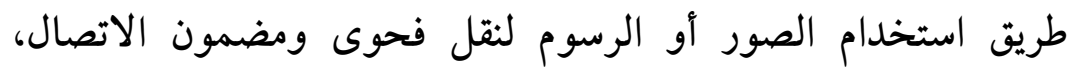

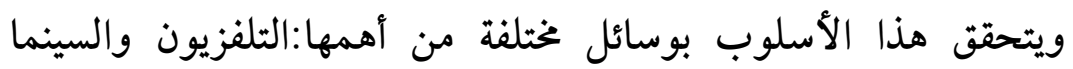
والصور التي يتم نشرها في الصحف والمجلات والإعلانات (30).

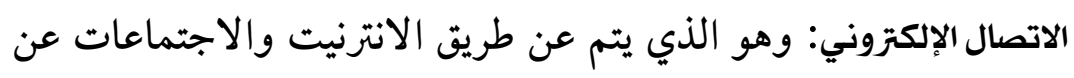

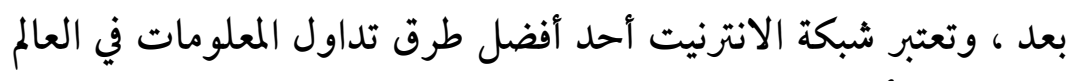

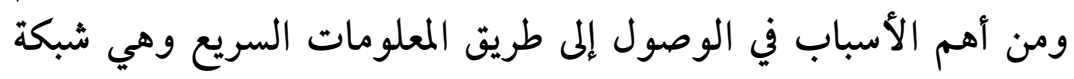

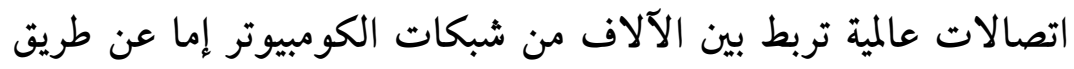
خطوط الهاتف أو عن طريق الأقمار الصناعية (31).

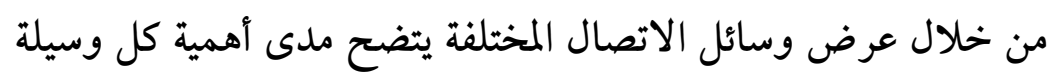

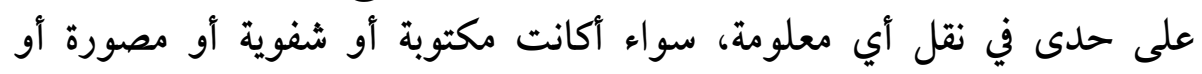

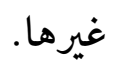
ب - نظريات الاتصال في الفكر الإداري:هناك بجموعة من النظريات التي ساهمت في

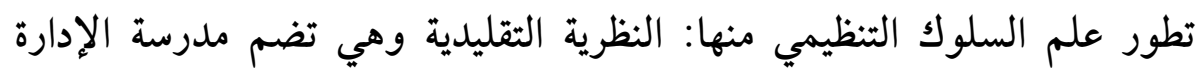

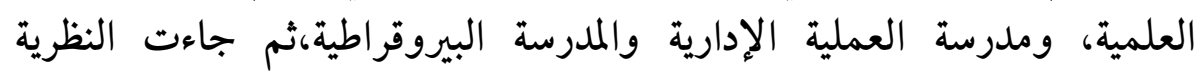

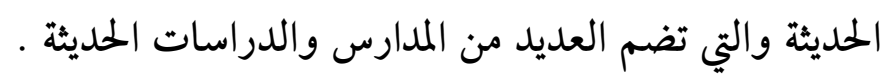
النظريات التقليدية:ومن أهمها مدرسة الإدارة العلمية، ومدرسة العماتية العماتية

$$
\text { الإدارية والمدرسة البيروقراطية. }
$$

\# مدرسة الإدارة العلمية: استهلفت حركة الإدارة العلمية تكوين توجه

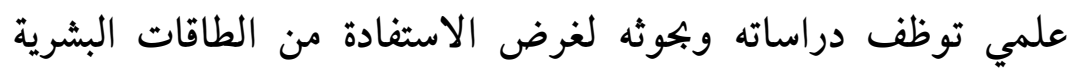

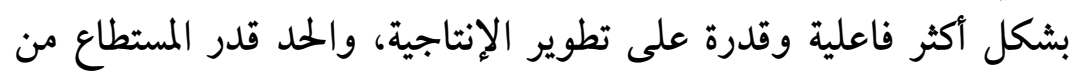

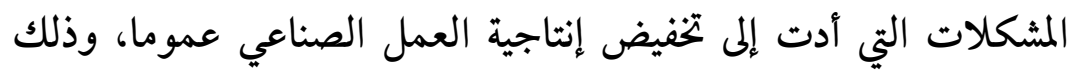

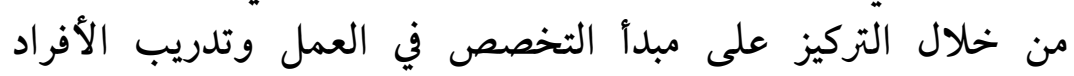
العاملين واعتماد الحوافز المادية في تشجيع الأداء الإنتاجي (32). 
ونتيجة لتلك الدراسات والتجارب توصلت حركة الإدارة العلمية والتي تقترن بالكاتب الأمريكي فريدريك ونسلو تايلور

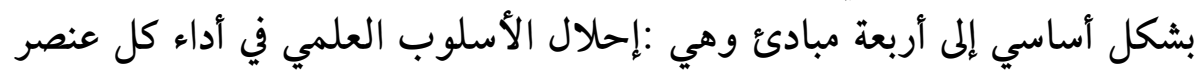

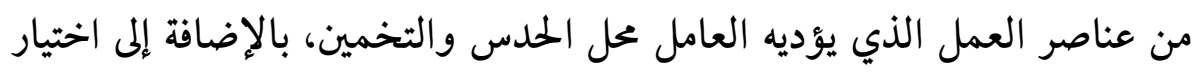
العاملين وتدريبهم وفق أسس علمية.

كما تنادي إلى تعاون الإدارة والعاملين لتحقيق أهداف العمل وفق الأسلوب

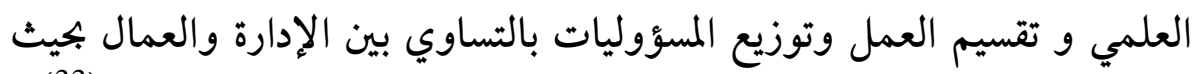
تتولى الإدارة مسؤولية التخطيط والإشر اف ويعهد للعاملين مسؤولية التنفيذ (33).

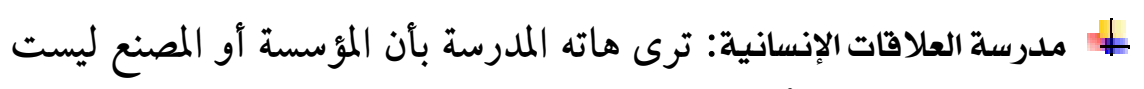

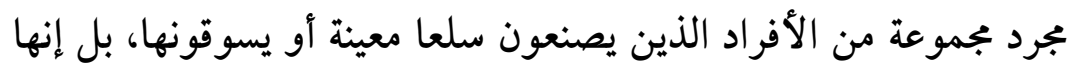

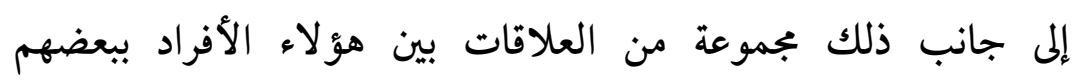
البعض.والعلاقات الإنسانية بين العاملين تظهر واضحة في في العان الاحترات المتبادل والثقة والتعاون.والحقيقة أن موضوع العلاقات الإنسانية بين

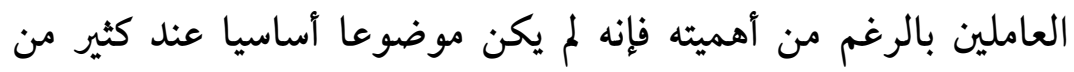

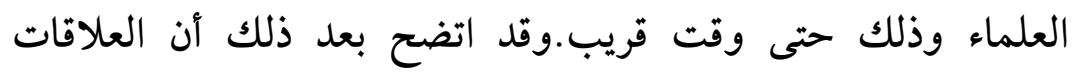

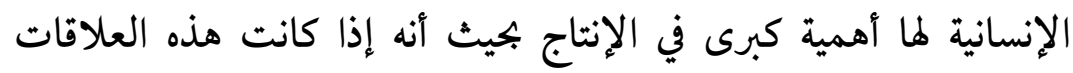

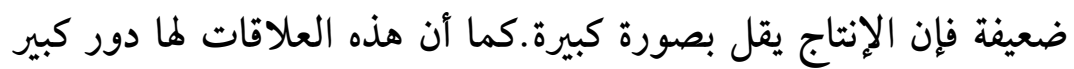
في إصابة العامل بالأمراض النفسية وقد تؤدي بالعامل إلى ترك إن عمله، والتقلب بين الوظائف، وذلك إذا كانت هذه العلاقات ضعيفة النفية (34). النظريات الحديثة: نذكر من بينها:المقاربة الوظيفية- النظرية الموقفية ونظرية المعلومات.

| المقاربة الوظيفية: تعتبر المؤسسة ككل عضوي يقيم أداؤه من خلال الوظائف الظاهرة والكامنة التي تؤديها مختلف عناصره، الؤهن كما يعتبر الهيكل

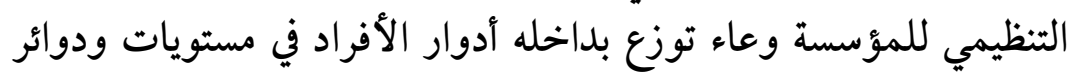
وحدود مختلفة، وهو مستقل في وجوده عن العمليات التي تسببت في 
إنشائه وتغييره، فالاتصال يعتبر مادة ملموسة تنتقل أفقيا وعموديا(صعودا

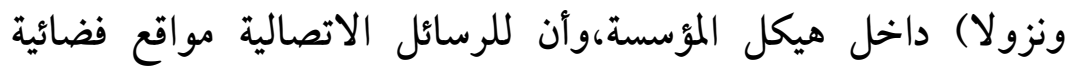

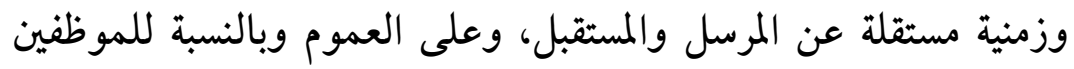

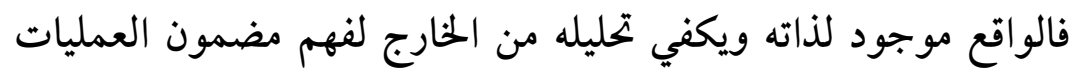

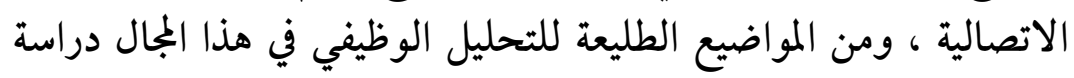

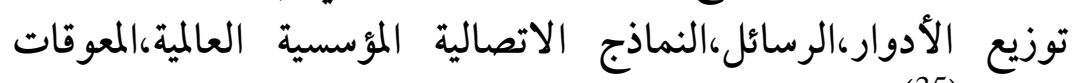
وغيرها (35).

| نظرية النظم:وتعتبر من النظريات الحديثة وتوفر لعلماء الإدارة

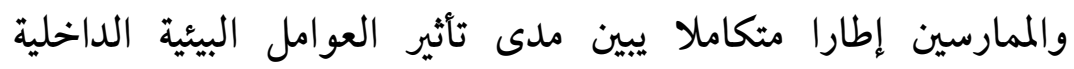

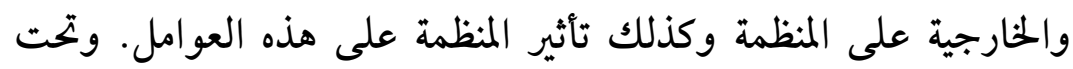

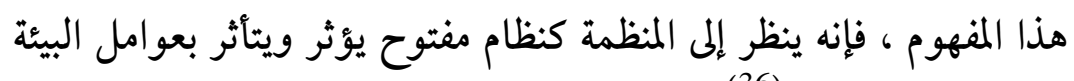

$$
\text { الداخلية والخارجية (36). }
$$

كما قدمت مساهمات خاصة حول الاتصال وهي تنظر إلى منظمات

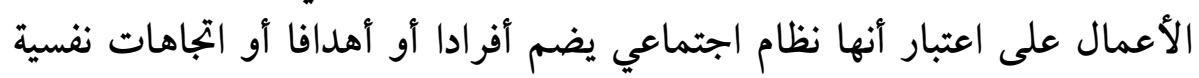

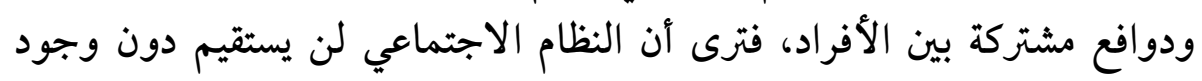
اتصالات تؤثر فيه بجيوية، وترى نظرية النظم:

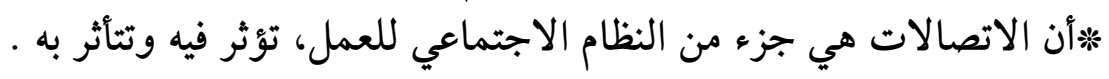

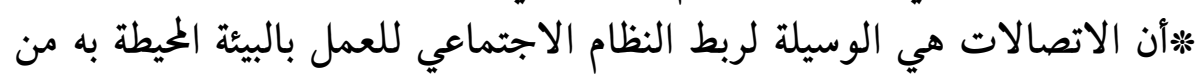
منظمات أخرى، عملاء وموردين، ومساهمين وغيرها.

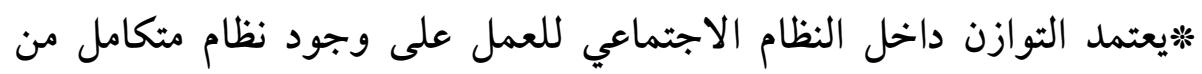
الاتصالات الذي يربط أجزاؤه وأفراده. *قأنه باختلاف الظروف (مثل أطراف الاتصال، وموضوع الأفراده الاتصال وغيرها)،

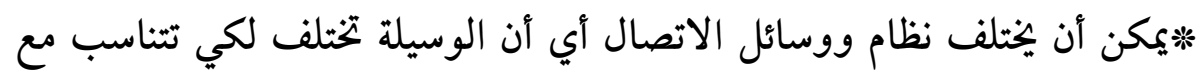
الظروف.

وهكذا فإن الاتصال يعتبر نظام متكامل للربط بين أجزاء النظام ككل. 
4 نظرية المعلومات: تقدم نظرية المعلومات بعض المساهمات في نظرية الاتصالات فهي ترى أن الاتصالات عبارة عن مجموعة الأنشطة الخاصة

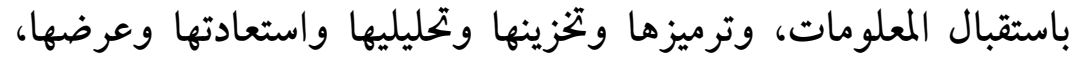

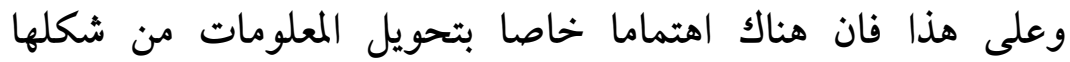

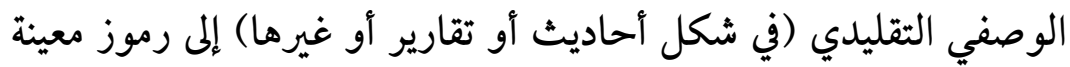

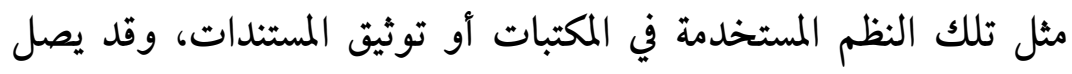

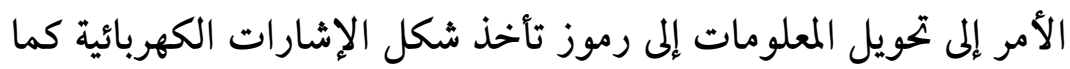

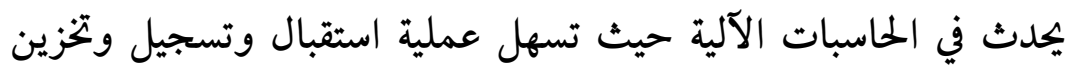

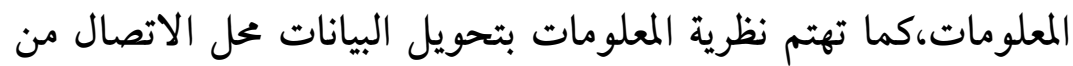

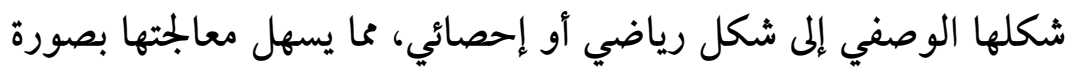
أسرع (37)

مميزات الاتصال الفعال: نحددها فيما يلي (38): تقوية العلاقات- يساعد في بناء الثقة والتعاون- يساعد على إزالة اللبس وسوء

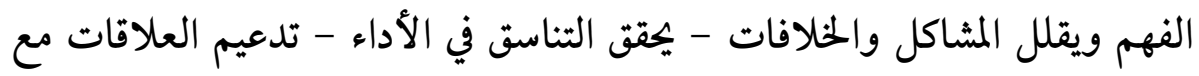

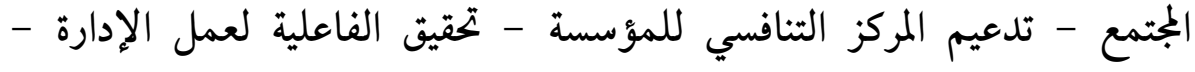

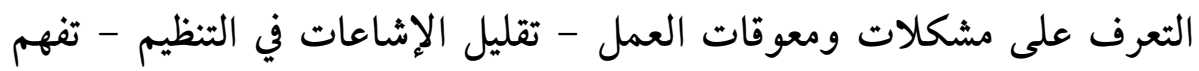
الفرد للعمل المكلف به - تدعيم مفهوم العلاقات الإنسانية.

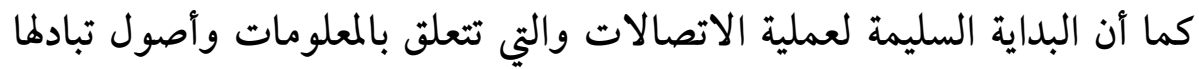

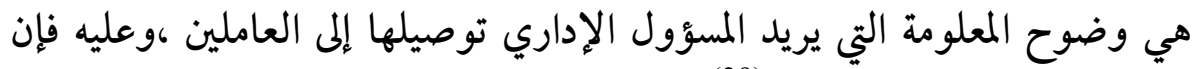
خطوات الاتصال الفعال هي (39): • إصدار التعليمات: وفي هذه الخطوة تنحصر التعليمات اللازمة لحسن سير

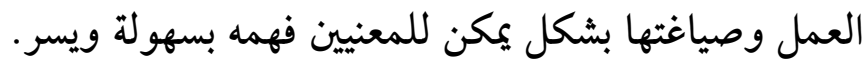

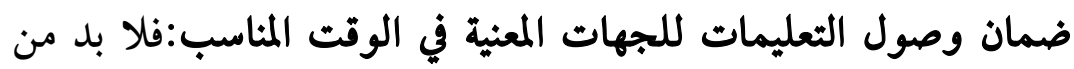
مراعاة اختيار الوسائل والقنوات المناسبة لنقل يختلف التعليمات. 
التاكد من متابعة التنفيذ والتقويم: فلا بد من مراقبة المنفذين والتأكد من قيامهم

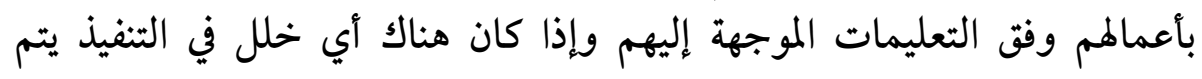
تصحيحه وتقويمه (40).

الخاتمة:

بعد عرضنا لمجمل العناصر المتعلقة بالموضوع يتبين أنه كلما انتهجت الإتهات

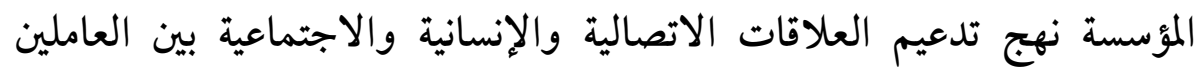

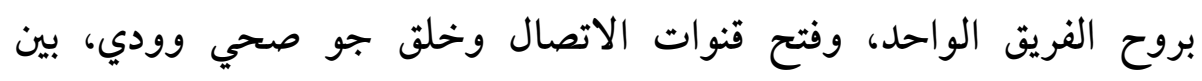

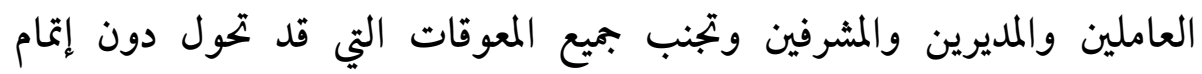

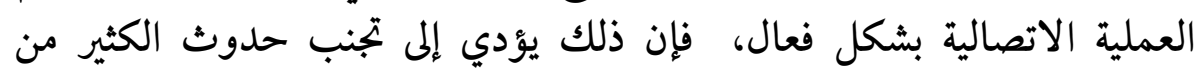

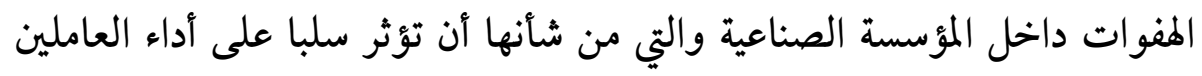
ونشاطات المؤسسة، وتعزيز فرص تحقيق أهدافها. 


\section{هوامش البحث:}

دادي عدون ناصر: الاتصال ودوره في كفاءة المؤسة الاقتصادية - دراسة نظرية

$$
\text { وتطبيقية- ، دار المحمدية ، الجزائر، 2004، صدون الاتهال ودوه في كفة }
$$

(2) عبد الحميد البدري طارق: الأساليب القيادية والادارية في المؤسسات التعليمية، ط2، دار الفكر، عمان الأردن، 2005، صميد :146. (3) شاكر البكري إياد:تقنيات الاتصال بين زمنيين، دار الشروق، عمان، الأردن، 2003، ص :17. (4) سلمان العميان محمود: السلوك التنظيمي في منظمات الأعمال، ط3، دار وائل، عمان، الأردن ، 2005، ص :237.

$$
\text { (5) بن نوار صالح : مرجع سابق، ص :34. }
$$

(6) قاسم القريوتي محمد: السلوك التنظيمي- السلوك الإنساني الفردي والجماعي في

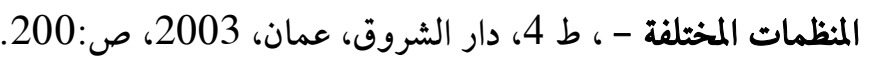
(7) مصطفى العليان ربحي، محمد الطوباسي عدنان: الاتصال والعلاقات العامة، دار الصفا،

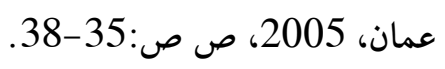
(8) السيد عبيد ماجدة: الوسائل التعليمية في التريية الخاصة، دار الصفاء، عمان، 2000، ص:30.

(9 محمد أبو شنب جمال: نظريات الاتصال والإعلام - المفاهيم - المداخل النظرية القضايا، 2006، ص:15. (10) دليو فضيل: مقدمة في وسائل الاتصال الجماهيرية، ديوان المطبوعات الجامعية،الجزائر، 23: 1998،ص فصن: مقدم (1) عبد الحميد البدري طارق :مرجع سبق ذكره،ص:147. 


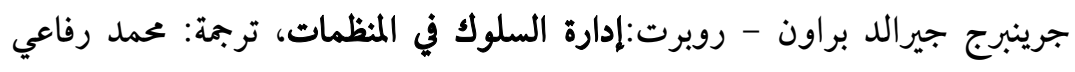

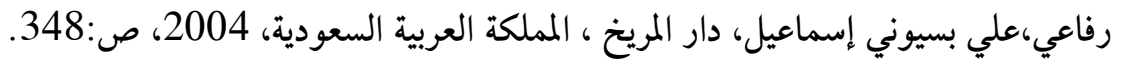

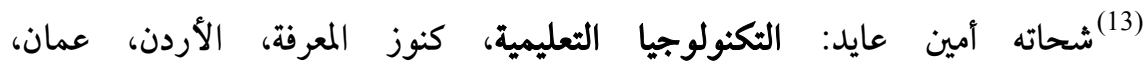
2006 2006،ص:52.

لبيب الطاهربيضون اليأس: الموسوعة العربية للمعرفة من اجل التنمية المستدامة البعد

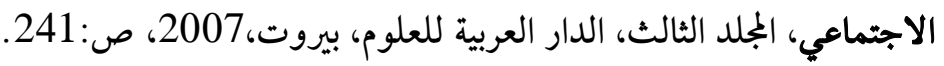

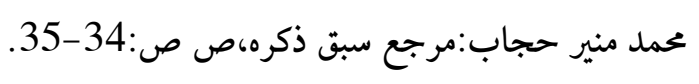

أوهايية فتحية، نواري أمال:الاتصال الجمعوي -اشكاله -اجياله- وساثله

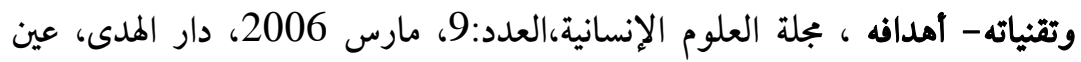

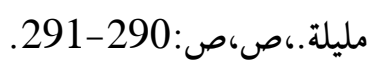

(17) الصريفي محمد :الاتصالات الإدارية سلسلة إصدارات الثدريب الإداري ، مؤسسة الإنة

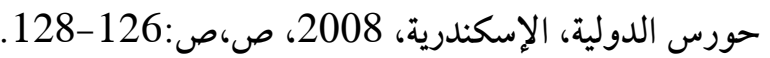

$$
\begin{aligned}
& \text { سلمان العميان محمود:مرجع سبق ذكره، ص:250. }
\end{aligned}
$$

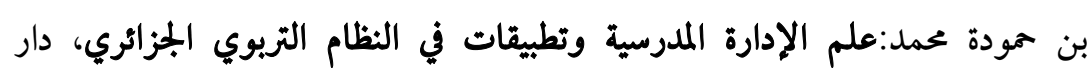

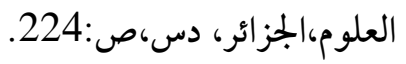

$$
\text { محمد منير حجاب:مرحع سبق ذكره، ص:50. }
$$

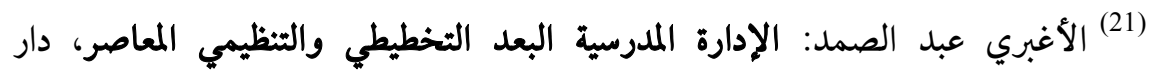

$$
\text { النهضة، بيروت، 2000، ص:50. }
$$

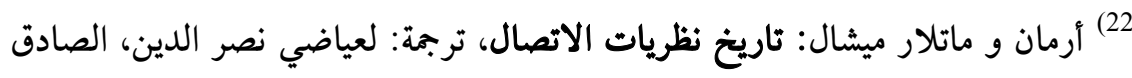

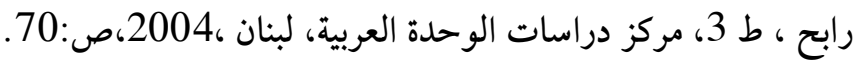

$$
\text { الاغبري عبد الصمد:مرجع سبق ذكره، ص:53. }
$$


حسين إسماعيل محمود: مبادى علم الاتصال ونظريات الثائير، الدار العالمية، شارع

$$
\text { الملك فيصل ، 2003،ص:215. }
$$

حجازي مصطفى: الاتصال الفعال في العلاقات الإنسانية والإدارة، دار الطليعة، لبنان،

$$
\text { 1982، ص ص:20152 }
$$

أحمد ماهر:كيف ترفع مهاراتك الإدارية في الإتصال، الدار الجامعية،الإسكندرية،

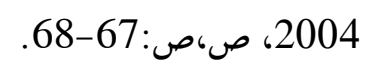

$$
\text { حجازي مصطفى :مرجع سبق ذكره،ص:156. }
$$

(28)رفعت عبد الوهاب محمد، شيحا إبراهيم عبد العزيز :أصول الإدارة العامة، دار

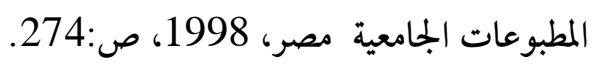

(29) الدويك تيسير وآخرون: أسس الإدارة التربوية و المدرسية، ط2، دار الفكر، عمان،

$$
\text { 1998،ص:276. }
$$

محمد رفعت عبد الوهاب، إبراهيم عبد العزيز شيحا: مرجع سبق ذكره، ص:274.

منير حجاب محمد: الموسوعة الإعلامية، مجلد 1، دار الفجر، 2003 ص ص :65-

محمد حسن الشماع خليل: نظرية المنظمة، دار المسيرة، عمان، 2000، ص:44.

حريم حسن :إدارة المنظمات منظور كلي، دار الحامد،عمان، الأردن، 2003، ص:21. كمال طارق: علم النفس المهني والصناعي، مؤسسة شباب الجامعة، الاسكندرية،

$$
\text { 2007، ص: 165. }
$$

(35) دليو فضيل :اتصال المؤسسة -اشهار -علاقات عامة مع الصحافة، ط3، دار الفجر،

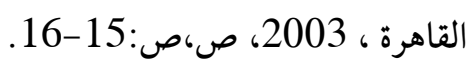

(36) درة عبد الباري، جودة محفوظ: الأساسيات في الإدارة المعاصرة منحنى نظامي، دار

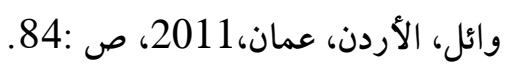




\section{العدد 15:.......... جوان 2015}

$$
\text { ماهر أحمد :مرجع سابق ، ص،ص:37) 3837. }
$$

حسين حمودة رامي: مفاميم حديثة في وظاثف الادارة التربوية والتعليمية، دار

أسامة، الأردن، عمان، دس، صردة :140.

$$
\text { هاشم حمدي رضا،مرجع سبق ذكره:ص ص 106-107. }
$$

محمد موسى فتحي: العلاقات الانسانية في المؤسسات الصناعية، دار زهران، عمان

$$
\text { الأردن، 2009،ص ص: صن: 183-184. }
$$

